\title{
"Sem cuja approvaçaio me naĩ atrevo a obrar nada": edição e estudo filológico de carta setecentista do Estado do Grão-Para e Maranhão
}

\author{
"Sem cuja approvaçaõ me naõ atrevo a obrar nada": \\ edition and philological study of an eighteenth-century letter \\ of the State of Grão-Pará and Maranhão \\ Phablo Roberto Marchis Fachin \\ Universidade de São Paulo (USP) \\ Marina Pessoa Silva \\ Universidade de São Paulo (USP) \\ DOI: https://doi.org/10.5902/2176148541146
}

Resumo: Neste artigo, apresenta-se o estudo de carta enviada por Gonçalo Pereira Lobato e Sousa a Francisco Xavier de Mendonça Furtado, Governador e capitão general do Estado do Grão-Pará e Maranhão no período de 1751 - 1759. O estudo faz parte de pesquisa mais ampla, cujos objetivos são a edição semidiplomática e o estudo filológico de documentos manuscritos do século XVIII, da região norte do país, no "Período Pombalino". Integra os trabalhos do Grupo de Pesquisa ETeP - Edição de Texto em Português (FFLCH-USP). Trata-se de análise linguísticohistórica, com o objetivo de contribuir para os estudos sobre a História da Língua Portuguesa.

Palavras-chave:Filologia.Linguística Histórica. Língua Portuguesa.Edição semidiplomática. Grão-Pará e Maranhão.

Abstract: This article presents the study of a letter sent from Gonçalo Pereira Lobato e Sousa to Francisco Xavier de Mendonça Furtado, Governor and Captain General of the State of Grão-Pará and Maranhão, from 1751 to 1759. The study is part of a larger research whose aims are the semidiplomatic edition and the philological study of manuscript documents of the eighteenth century, from the northern region of the country, in the "Pombaline Period". It integrates the works of the Research Group ETeP - Portuguese Text Edition (FFLCH-USP). This is a linguistic-historical analysis, with the objective of contributing to the studies on the History of the Portuguese Language.

Keywords: Philology. Historical Linguistics. Portuguese language. Semidiplomatic edition. Grão-Pará and Maranhão. 


\section{Introdução}

A prática epistolar, no contexto administrativo colonial especificamente, ocorria em meio a uma produção documental ampla e complexa, como uma das maneiras mais comuns de comunicação. Encontram-se

Phablo correspondências desse tipo entre os mais variados cargos, com difeRoberto renças gráficas e formais muito significativas, de acordo com o nível Marchis de proximidade entre seus interlocutores e de domínio linguístico dos Fachin responsáveis materiais e intelectuais pela sua produção. Trata-se de um

Marina Pessoa

Silva conjunto diversificado de construções textuais, embora com estrutura tipológica muito semelhante.

Mesmo sob ordens régias portuguesas, em teoria, com forma pré-determinada de administração, cada capitania apresentava particularidades naturais no processo de governo, devido, muitas vezes, às características da região, de suas demandas e do povo que ali estava em contato, determinando dinâmicas divergentes, o que poderia implicar também uma diferenciação da produção e da circulação documental, em uma época na qual a administração também era feita por meio de tinta, pena e papel. Tendo em vista esses aspectos comunicativos e de produção manuscrita, ainda é emergencial o estudo sistematizado dessas práticas, de acordo com cada contexto local administrativo, para que se possa compor um quadro representativo das práticas de escrita ao longo da América Portuguesa. Um estudo que, embora com muitos avanços, ainda está por fazer, uma parte pelo número documental pouco expressivo diante do conjunto de onde foi retirado; outra por ainda haver regiões brasileiras nas quais os estudos filológicos e linguísticos ainda são bem escassos, como é o caso da região conhecida como Grão-Pará e Maranhão.

No caso da região norte do Brasil setecentista, da qual fazem parte os manuscritos que compõem o corpus deste estudo, a maior dificuldade estava no campo geográfico, que gerava grandes transtornos no processo de circulação de documentos. Essa região, especificamente o Estado do Grão-Pará e Maranhão, compunha uma unidade administrativa separada do Estado do Brasil, favorável a vários interesses da coroa portuguesa. Francisco Xavier de Mendonça Furtado e Gonçalo Pereira Lobato e Sousa são dois personagens importantes para a trajetória das capitanias dessa região. 0 primeiro, meio irmão do Marquês de Pombal, era governador e capitão-general no período de 1751-1759. O segundo, capitão general do Maranhão, nomeado por Mendonça Furtado em 1753. Os administradores coloniais ocupavam um lugar bastante conhe- 
cido e importante na história do Brasil. Francisco Xavier de Mendonça Furtado compõe o quadro na região norte, como um dos principais nomes no processo de restauração das conquistas setentrionais, entre outros feitos em sua trajetória como administrador colonial.

Por sua relevância histórica, a produção documental ao longo do Brasil colonial foi extensa e ainda pode contribuir significativamente com os estudos realizados, ampliando a visão sobre essa região, tanto do ponto de vista social, cultural e político quanto linguístico. Contribui-se, dessa forma, para o conhecimento de práticas de escritas na administração da colônia e do uso que se fazia da língua portuguesa no contexto das práticas de escrita administrativa no Estado do Grão - Pará e Maranhão. A complexidade da historiografia da região norte apresenta-se, portanto, como objeto de estudo considerável para compor aspectos do

"Sem cuja approvaçaõ me naõ atrevo a obrar nada" desenvolvimento linguístico e social do Brasil no século XVIII. Tendo em vista esse fato e com base nos princípios filológicos, do estudo apurado de textos escritos, da sua história e do contexto de produção, neste artigo apresenta-se parte de um estudo em andamento a respeito de cartas enviadas por Gonçalo Pereira Lobato e Sousa a Francisco Xavier de Mendonça Furtado. Busca-se, por meio da análise de manuscritos administrativos em circulação na região em questão, contribuir para os estudos sobre a história do português e para a composição do cenário histórico brasileiro, em especial da região norte do país.

A escolha de documentação dessa localidade se dá justamente pela escassez de análises filológicas de textos produzidos nesse contexto, seja por portugueses ou brasileiros. Procura-se compreender como se compunham em sua materialidade e escrita, tendo em vista a relação com seu processo de produção e circulação diante de um contexto histórico específico, considerando espaço, tempo e sociedade. Este estudo faz parte de pesquisa mais ampla, cujos objetivos são a edição semidiplomática de trinta e cinco cartas produzidas nesse período e contexto, passivas a Mendonça Furtado, datadas entre 1751-1757. Para além da edição, descrevem-se e analisam-se aspectos linguísticos que caracterizam a língua portuguesa, assim como seu processo de produção e circulação, buscando identificar uma possível tradição gráfica setecentista no contexto administrativo.

Este artigo divide-se em quatro partes. Na primeira, abordam-se aspectos gerais que caracterizam a importância do século XVIII no Brasil. $\mathrm{Na}$ segunda, apresentam-se o manuscrito selecionado, suas característi- 
cas e a edição semidiplomática do documento. Na terceira, apresentam-se os administradores e a administração colonial da região norte no período. Na quarta, implicações linguísticas da escrita do manuscrito.

Phablo O século XVIII e sua importância na construção da Roberto história do Brasil

Marchis $\quad 0$ século XVIII mostra-se como um período de extrema importância na Fachin construção da história do Brasil e de Portugal. A necessidade de organização das colônias era urgente em todos os aspectos. A organização so-

Marina Pessoa

Silva cial, política, e sobretudo, econômica, era um ponto crucial para a manutenção dos domínios da coroa portuguesa. A descoberta do ouro no final do século XVII, que movimentou o centro do país, e as posteriores invasões francesas e espanholas reforçaram a necessidade de expansão e fixação das fronteiras por meio da coroa.

Na segunda metade do século XVIII, é possível observar o crescimento das ideias iluministas, com a consequente expulsão dos jesuítas e a instauração, do que ficou conhecido na historiografia regional brasileira, como período pombalino. Para a região norte, esse período configura um forte estabelecimento da administração colonial, como apresenta Fontanelle:

\footnotetext{
Nesse sentido, quando falamos de Grão-Pará na segunda metade do século XVIII, referimo-nos a um período da história regional que ficou conhecido na historiografia como período pombalino, no qual políticas foram implementadas no sentido de reformar a administração colonial na região. Assim como nas outras áreas do vasto império português, o governo metropolitano promoveu reformas, cujos resultados dependiam das relações sociais vivenciadas nas colônias (FONTANELLE, 2008, p. 14).
}

Os desdobramentos administrativos apresentam-se como influência significativa para a formação do país, assim como a relação entre seus administradores, em especial os da região norte (Grão-Pará e Maranhão), em que o período pombalino sob o governo de Francisco Xavier de Mendonça Furtado, meio irmão do Marquês de Pombal e primeiro governador e capitão-general, tornou-se decisivo para o futuro daquelas regiões relacionadas diretamente com a coroa Portuguesa. 


\section{O manuscrito}

O manuscrito que compõe a análise deste artigo está localizado na Biblioteca Nacional de Portugal - BNP, catalogado na coleção José António Moniz, que intitulou o conjunto como "Cartas e documentos pertencentes ao governo de Francisco Xavier de Mendonça Furtado nos estados do Maranhão e Grão Pará, relativos à administração pública, índios, missões, conquistas, bicho da seda. 1746-1757"- Inventário. Secção XIII - Manuscriptos Collecção Pombalina. Lisboa: BN, 1889.

Dentre o conjunto das trinta e cinco cartas, que serão analisadas posteriormente, deve-se uma composição total de cento e cinquenta fólios, recebidas por Francisco Xavier de Mendonça Furtado, em sua maioria, escritas pelo capitão general do Maranhão Gonçalo Pereira Lobato e Sousa (dezoito cartas), mais dezessete escritas por autores va-

"Sem cuja approvaçaõ me naõ atrevo a obrar nada" riados, optou-se pela análise da carta com datação de 10 de novembro de 1757. De acordo com a seleção feita na BNP essa carta foi a última encontrada no registro do banco de dados. Importante ressaltar que a seleção no banco de dados da BNP foi feita com base em um período, de 1750 até 1760 , uma década portanto. A primeira carta do conjunto tem a data de 29 de dezembro de 1751, e a última dia 10 de novembro de 1757. Nessa busca, identificou-se uma recorrência de cartas enviadas a Francisco Xavier de Mendonça Furtado, o que suscitou um cuidado e interesse em separar e analisar essas cartas, a fim de identificar aspectos que pudessem ampliar os estudos filológicos, assim como os estudos nos demais campos na interdisciplinaridade que nos proporciona a análise filológica. Seguem imagens de uma das cartas. 


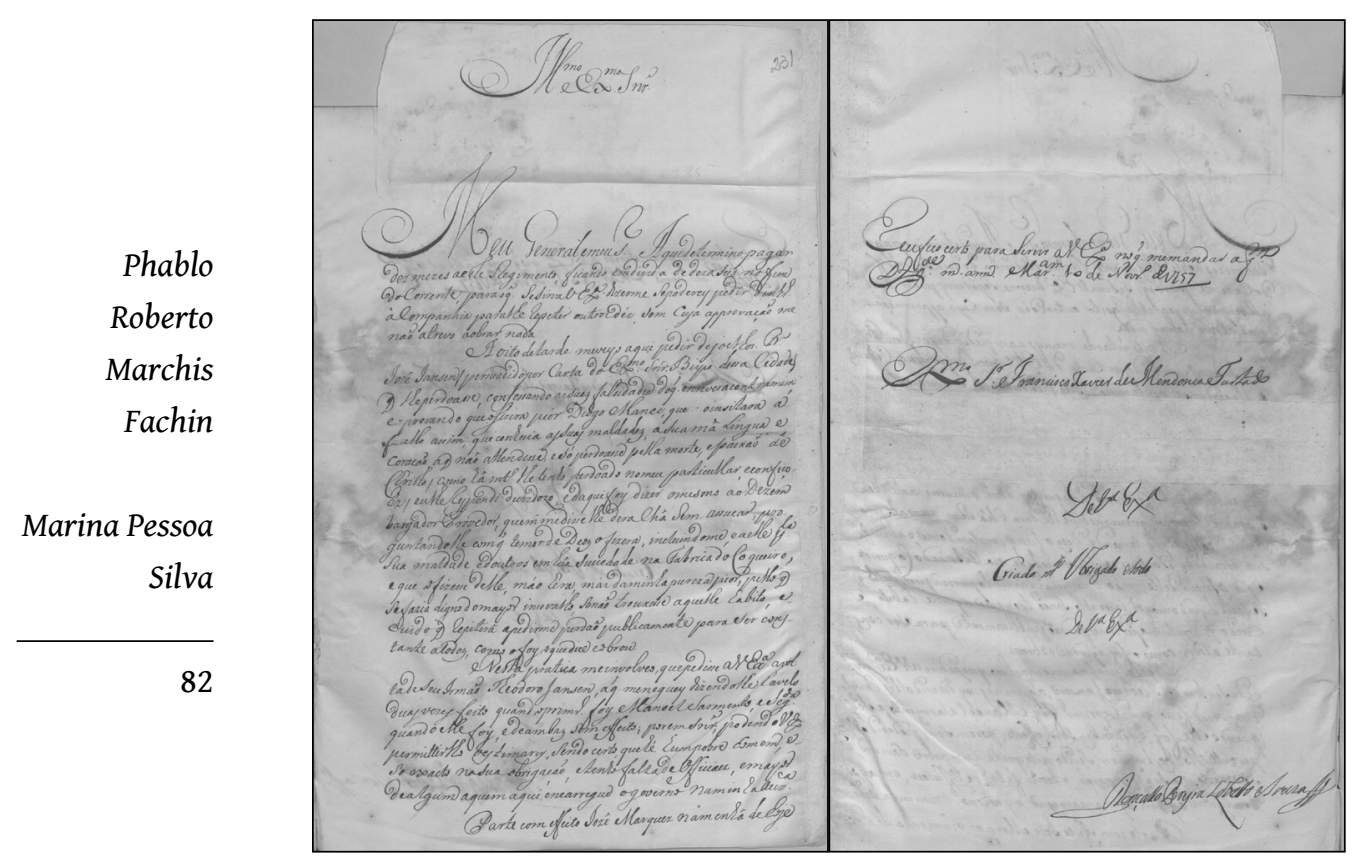

Figura 1. Carta datada de Maranhão, 10 de novembro de 1757, assinada por Gonçalo Pereira Lobato e Sousa.

O labor filológico consiste em editar, identificar e estudar os documentos e suas práticas de escrita. Com isso, verificam-se as relações com o português e seus processos linguísticos fundamentais para a comunicação. Observando a construção de uma possível tradição gráfica administrativa colonial, busca-se destacar como os hábitos de escrita presentes na carta selecionada se relacionam com o que conhecemos da história do português setecentista, e como seu contexto de produção pode ter sido influenciado.

Inicia-se a análise de acordo com a Diplomática. Definida desde sua origem formal no século XVI, como o estudo da "descrição e explicação da estrutura formal dos atos escritos, sua autenticidade e sua fidedignidade" (BELLOTO, 2002, p.13). Nesse período o seu objetivo teria sido provar a "autenticidade formal dos documentos". Entretanto, a diplomática encontra-se hoje em outro patamar em que a análise "concentra-se na gênese, na constituição interna, na transmissão e na relação dos documentos entre seu criador e o seu próprio conteúdo, com a finalidade de identificar, avaliar e demonstrar a sua verdadeira natureza" (BELLOTO, 2002, p.17). Isso posto, podemos identificar a importância desse tipo de análise, para que se evitem equívocos quanto à consolidação do que 
seria no documento a "tradição documental" apresentada, e a "questão da autoria" do manuscrito. De acordo com Fachin, são dois aspectos fundamentais para o "estudo do estado da língua" e as "implicações da produção e difusão de documentos no Brasil colonial":

\begin{abstract}
No primeiro caso, devemos considerar que os documentos produzidos na esfera administrativa colonial se enquadravam numa tradição documental de tipologias compostas por diversas espécies documentais, as quais respeitavam uma estrutura diplomática formal, cada qual com suas partes e fórmulas de escrita. Escrever naquela época e situação implicava, portanto, conhecer tais estruturas e fórmulas e saber aplicá-las de acordo com a necessidade administrativa. Consequentemente, de acor-
\end{abstract}

"Sem cuja approvaçaõ me naõ atrevo a obrar nada"

Para a análise diplomática, é necessário considerar a espécie documental diplomática, que, de acordo com a definição de Belloto, “é aquela que obedece a fórmulas convencionais, em geral estabelecidas pelo Direito administrativo ou notarial" (BELLOTO, 2002, p. 27). Mesmo para documentos que não se enquadram nesse contexto, como o caso das cartas do projeto, havia uma estrutura que costumava se repetir, configurando-se o documento de maneira mais ou menos sistematizada. Cabe ainda identificar a definição da espécie documental carta apresentada por Bellotto.

\footnotetext{
Correspondência do alto escalão da administração pública em comunicações sociais decorrentes de cargo e função públicos. Nas entidades privadas da área comercial, industrial, bancária, social entre outras, a carta é uma forma de correspondência largamente utilizada para transmitir informações, solicitar favores, fazer convites etc. Sem ser obrigatório, diplomaticamente, há uma certa padronização (BELLOTO, 2002, p. 51).
} 
De acordo com a estrutura apresentada de "certa padronização", a carta aqui analisada apresenta-se da seguinte forma:

\section{Quadro 1. Composição de Carta.}

Phablo

Roberto

Marchis

Fachin

Marina Pessoa

\begin{tabular}{|c|c|}
\hline $\begin{array}{c}\text { Espécie } \\
\text { documental }\end{array}$ & Carta \\
\hline $\begin{array}{c}\text { Protocolo } \\
\text { Inicial }\end{array}$ & $\begin{array}{l}\text { 1757, Novembro } 10 \\
\text { Illustrissimo eExcelentissimoSenhor } \\
\text { Meu General, emeu Senhor Aquidetermino pagar } \\
\text { dez mezes aesteRegimento, ficando emdivid a de dezaSeis no fim... }\end{array}$ \\
\hline Texto & $\begin{array}{l}\quad \text { A [oito] detarde meveyo aqui pedir dejoelhos. Frei } \\
\text { Iozê Iansen/persuadidoper Carta do Excelentissimo Senhor̃ Bispo dess } \\
\text { aCidade[s] } \\
\text { que lheperdoasse, confessando asSuaz falsidadez do q́ue } \\
\text { escreveracontramim } \\
\text { e provando queofizera pior Diogo Manec, que [ ] o insultara á } \\
\text { of[end]ello] assim, que conhecia asSuas maldadez, aSuamâ Lingua e } \\
\text { coracaõ aque não attendesse, eSó perdoasse pella morte, epaixaõ de } \\
\text { Christo/ como hâ muitos lhe tenho perdoad o nomeu particullar, } \\
\text { econfiço- } \\
\text { éz/eulherespondi duvidozo, ed aquifoy dizer omesmo ao Dezem } \\
\text { bargadorProvedor, quemmedisse lhe deraChâ Sem assucar, pro- } \\
\text { guntandolhe comq́ue temord e Deoz ofizera, incluind ome, eaelle [pela] } \\
\text { Sua maldade edoutros emhuâ Suciedade na Fabrica d oCo queiro, } \\
\text { eque ofizesse delle, máo hera, máz daminhapureza pior, pelloque } \\
\text { Sefazia digno d omayor inso valho, Senaõ trouxesse aquelle habito, e-... }\end{array}$ \\
\hline $\begin{array}{l}\text { Protocolo } \\
\text { Final }\end{array}$ & $\begin{array}{l}\text { Eeufico certo paraServir aVossa Excelencia noq́ue memandar a fazer } \\
\text { Deus guarde muitos annos Maranham } 10 \text { de Novembro d[e]1757 } \\
\text { Excelentissimo Senhor Francisco Xavier deMendoncaFurtado } \\
\text { De Vossa Excelencia } \\
\text { Criado muito Ubrigado etodo } \\
\text { De Vossa Excelencia } \\
\text { Gonçallo Perejra Lobatto eSouza }\end{array}$ \\
\hline
\end{tabular}

A carta segue uma padronização em sua composição seguindo o modelo protocolo inicial, texto e protocolo final. O destinatário da carta é Francisco Xavier de Mendonça Furtado, que historicamente manteve uma relação próxima com o Brigadeiro Gonçalo Pereira Lobato e Sousa, com quem tratava de assuntos referentes à administração do Maranhão. A formulação do texto também segue o padrão da espécie documental carta, mostrando uma forma mais livre de escrita. Os protocolos inicial e final evidenciam uma relação de formalidade e respeito em que é passível de verificação, no caso apresentado, uma certa disposição para 
uma subordinação administrativa, comprovada pela frase que intitula o presente artigo e nos dá pistas das relações estabelecidas na administração colonial.

Mais detalhadamente, essa primeira organização subdivide-se em: "Protocolo inicial: datas tópicas e cronológicas. Endereçamento. Direção. Texto: paragrafado, com exposição e o objetivo da carta. Protocolo final: fecho de cortesia, assinatura, nome e cargo do signatário". (FACHIN, 2011, p.40). Essas características estão presentes na carta de Gonçalo Pereira a Mendonça Furtado, e serão confrontadas nas demais cartas que compõem o material de pesquisa em estudo posterior.

\footnotetext{
Apesar de não possuírem obrigatoriamente uma estrutura preestabelecida, possuem características comuns que possibilitaram o seu agrupamento. Apresentam no início o nome ou forma de tratamento para quem se destina o documento, geralmente "Senhor", “Vossa Majestade”, “Vossa Excelência” ou, até, "Meu Senhor", de acordo com a relação entre os correspondentes. Em seguida, vem o teor da carta com a exposição do assunto que a motivou. Por fim, o fecho de cortesia, seguido pela indicação das datações tópica e cronológica e a assinatura. Quando se trata de treslado, essa informação abre o documento (FACHIN, 2011, p. 40).
}

\section{"Sem cuja approvaçaõ me naõ atrevo a obrar nada"}

\section{Edição semidiplomática da carta selecionada}

A edição escolhida para a carta estudada é a semidiplomática, pois preserva-se o estado de língua em que os documentos foram escritos, ao mesmo tempo, que se facilita a sua leitura, reparando-se problemas decorrentes de cópias ou deteriorações diversas. A transcrição realizada segue as "Normas para Transcrição de documentos para a História do Português do Brasil”, (CAMBRAIA; CUNHA; MEGALE, 1999, p. 23-6).

||r.

Illustrissimo eExcelentissimoSenhor

Meu General, emeu Senhor Aquidetermino pagar

dez mezes aesteRegimento, ficando emdivid a de dezaSeis no fim

doCorrente, para o que SeSirvaVossaExcelencia dizerme Sepoderey pedir dinheiro

5 àCompanhia paralhe repetir outrozdéz, sem Cuja approvaçaõ me naõ atrevo aobrar nada

A [oito] detarde meveyo aqui pedir dejoelhos. Frei 
Iozê Iansen $/{ }^{1}$ persuadidoper Carta do Excelentissimo Senhor̃ Bispo dess aCidade[s] que lheperdoasse, confessando asSuaz falsidadez do que escreveracontramim e provando queofizera pior Diogo Manec, que [ ] o insitara á of[end]ello] assim, que conhecia asSuas maldadez, aSuamâ Lingua e

Phablo

Roberto

Marchis

Fachin

Marina Pessoa

Silva

86 coracaõ aque não attendesse, eSó perdoasse pella morte, epaixaõ de Christo/ ${ }^{2}$ como hâ muitos lhe tenho perdoad o nomeu particullar, econfiçoéz/ ${ }^{3}$ eulherespondi duvidozo, ed aquifoy dizer omesmo ao Dezem bargadorProvedor, quemmedisse lhe deraChâ Sem assucar, proguntandolhe comq́ue temord e Deoz ofizera, incluind ome, eaelle [pela] Sua maldade edoutros emhuâ Suciedade na Fabrica d oCo queiro, eque ofizesse delle, máo hera, máz daminhapureza pior, pelloque Sefazia digno d omayor inso valho, Senaõ trouxesse aquelle habito, ecuid o que repitirâ aped irme perdaõ publicamente paraSer constante atodoz, como ofoy oquedice eobrou.

Nesta pratica me involveo, quepedisse a VossaExcelencia avoltadeSeu Irmaõ Theodoro Jansen, aq́ue meneguey dizendolhe havelo duas vezes feito quand oprimeiro foy ManoelSarmento, e Segunda quando elle foy, edeambaz Sem effeito ; poremSenhor̃; po dend o Vossa Excelencia permittirlhe oes timarey, Sendo certo, que hé humpobre homem, eSo exacto naSuaobrigação, etenhofaltad eOfficiaez, emayor dealgunz aquem aqui encarregue ogoverno Naminha auzencia Parte com effeito Iozê Marquez namenhâ dehoje

$\|1 \mathrm{v}$.

30 Eeufico certo paraServir aVossa Excelencia noq́ue memandar a fazer Deus guarde muitos annos Maranham 10 de Novembro $\underline{\mathrm{d}[\mathrm{e}] 1757}$

Excelentissimo Senhor Francisco Xavier deMendoncaFurtado De Vossa Excelencia Criado muito Ubrigado etodo

De Vossa Excelencia

Gonçallo Perejra Lobatto eSouza

1 Barra inclinada à direita do leitor. De acordo com Accioli (1994:53), configura-se como uma pausa na escrita do período.

2 Barra inclinada à direita do leitor com dimensão menor que a barra anterior e maior que as vírgulas recorrentes no texto.

3 Idem. 


\title{
Administradores e a administração colonial da região norte do Brasil em setecentos
}

\begin{abstract}
Ao chegar à administração colonial, Mendonça Furtado possuía a experiência militar valorizada nos titulares do governo das conquistas do Norte e a vivência dos problemas de fronteira entre os domínios portugueses e castelhanos. Na região platina, teve a oportunidade de experimentar situações similares às que enfrentaria anos depois no Pará e no Rio Negro. Nas expedições guarda-costas, aprendeu o valor de manter a integridade e a segurança dos territórios lusos, tanto na costa do Reino quanto nas possessões ultramarinas. Sendo assim, ao parentesco de Sebastião José de Carvalho e Melo somaram-se requisitos importantes (SANTOS, 2008, p. 53).
\end{abstract}

\section{"Sem cuja approvaçaõ me naõ atrevo a obrar nada"}

Francisco Xavier de Mendonça Furtado surge na historiografia da região norte como uma "personagem central na retomada da colonização amazônica no período pombalino" (SANTOS, 2008, p. 51). Em 24 de setembro de 1751, toma posse em Belém como o primeiro governador e capitão general do Estado do Grão-Pará e Maranhão, com o objetivo de "reorganizar a administração das conquistas do Norte" (SANTOS, 2008, p. 24). Constituindo uma unidade administrativa separada do Estado do Brasil, estava o Estado do Grão-Pará e Maranhão que tinha subordinação direta à Lisboa. Essa separação se deu tanto pela vastidão do território, quanto pelas condições naturais da região.

[...] é preciso considerar que as condições naturais tiveram papel fundamental na organização de duas unidades administrativas distintas na América portuguesa. Enquanto os ventos e as correntes permitiam que se viajasse mais facilmente de Lisboa para o Norte, a navegação para baixo do cabo de São Roque era complicada. [...] era mais rápida e segura a jornada da capital do Reino para São Luís do que desta cidade para Salvador. Sendo assim, a navegação na costa americana contribuiu para a fixação de um governo no Norte diretamente subordinado a Lisboa (SANTOS, 2008, p. 22). 
Essa organização administrativa de separação do Estado do Grão-Pará e Maranhão do Estado do Brasil, foi motivada por algumas questões como a necessidade de cultivo e povoação daquelas terras, justificativa usada pela Coroa Portuguesa, mas também pela necessiPhablo dade de "defesa do litoral do Pará e do Maranhão, assolados à época Roberto pelos franceses" (SANTOS, 2008, p. 22), e após expulsão desses, menMarchis cionava-se a necessidade da separação do governo "diante da dificulFachin dade de comunicação das terras do Norte com a sede do Governo-geral" (SANTOS, 2008, p. 23).

Marina Pessoa

Silva

A questão da dificuldade de comunicação interna seria uma das grandes motivações das disputas, assim como um dos maiores desafios da nova configuração administrativa que se instaurava com o governo de Francisco Xavier de Mendonça Furtado, que por sua vez, chegou à conclusão de que era mais produtivo estabelecer contato com Lisboa para de lá enviarem as cartas para a Bahia.

\footnotetext{
Por outro lado, a nova configuração administrativa não resolveu problemas que remontavam ao século XVII. O isolamento das conquistas do Norte e as dificuldades de comunicação interna persistiram. O primeiro aspecto pode ser exemplificado por meio de uma carta de Francisco Xavier de Mendonça Furtado ao vice-rei, D. Marcos José de Noronha e Brito, $6^{\circ}$ conde dos Arcos, comentando o envio de uma outra correspondência ao mesmo destinatário, em 9 de março de 1753, a qual só teria chegado ao destino ano e meio depois. Por conta disso, Mendonça Furtado tomou a decisão de "remeter as cartas por Lisboa, porque imagino que com maior brevidade chegarão à Bahia" (SANTOS, 2008, p. 35).
}

Contudo, para a ideia de uma nova organização administrativa que se formava no período pombalino, com a posse de Francisco Xavier de Mendonça Furtado, conforme aponta Santos, a mudança da capital para o Estado de Belém no lugar de São Luís, mostrou-se favorável às novas propostas para as conquistas do Norte. Observa-se que, mesmo diante dessa nova configuração, Belém não foi o foco da administração de Francisco Xavier de Mendonça Furtado, ainda que as diretrizes do governo pombalino tenham elevado Belém à condição de capital no lugar de São Luís, devido às estratégias de cumprimento do Tratado de Madri. 
A concretização dos planos metropolitanos no período pombalino alçou Belém à condição antes ocupada por São Luís. Mas, assim que chegasse à antiga capital do Estado do Maranhão, onde desembarcaria, Francisco Xavier de Mendonça Furtado deveria assegurar aos seus moradores que apesar de "a necessidade dos negócios e a utilidade do comércio" requererem a permanência do governador e capitão-general no Pará, "essa assistência em nada diminui[ria] os seus privilégios e preeminências". Com isso, evitar-se-ia qualquer sentimento de desprestígio da parte dos súditos do Maranhão que pudesse comprometer a realização dos projetos de revitalização das conquistas do Norte (SANTOS, 2008, p. 43-44).

Dentre os administradores coloniais da América Portuguesa, Francisco Xavier de Mendonça Furtado, historiograficamente, parece não integrar um lugar de honrarias. Santos (2008, p. 48) aponta a motivação de alguns depoimentos tão laudatórios como fáceis de entender, uma vez que Francisco Xavier de Mendonça Furtado deixaria "Belém com o objetivo de auxiliar o irmão que iniciava uma nova fase de sua carreira que ficaria marcada como a da "consolidação do poder" (17591765)". Destarte, há uma caracterização um tanto negativa sobre o perfil de Francisco Xavier de Mendonça Furtado em contraponto a depoimentos que lhe tecem grandes elogios e apreços.

Da sua administração, aspectos importantes a serem exaltados constam das 38 "instruções régias, públicas e secretas" que tinha por finalidade "nortear a sua administração e, por extensão, dos seus sucessores" (SANTOS, 2008, p. 58). Das instruções a primeira "contém os fundamentos da colonização portuguesa e a orientação da conquista e formação de um Império que não dispensava a promoção da evangelização, inerente à ocupação amazônica" (SANTOS, 2008, p. 59). A segunda instrução abre discussão para a questão dos índios

[...]um dos principais, senão o principal problema a ser solucionado na região: a liberdade e o uso da mão-de-obra dos índios. A maior parte das instruções foi dedicada ao tema e aos seus desdobramentos: reorganização das missões, das formas de exploração do trabalho indígena, a promoção do seu comércio e a introdução de escravos africanos (SANTOS, 2008, p. 60). 
Das instruções ainda constaria "o incentivo ao povoamento do vasto território amazônico, à agricultura e à defesa dos domínios confinantes com possessões de outras monarquias" (SANTOS, 2008, p. 61). 0 autor usa a definição dada por Isabel Vieira Rodrigues, para o processo

Phablo administrativo a que Francisco Xavier de Mendonça Furtado se submeRoberto teria em que "a ação colonizadora de Francisco Xavier de Mendonça Marchis Furtado consistiu em: fortificar, delimitar, povoar e desenvolver o EsFachin tado do Grão-Pará e Maranhão" (SANTOS, 2008, p. 61). Esse esquema foi continuado por seus sucessores.

Marina Pessoa

Silva

A trajetória pessoal de Francisco Xavier de Mendonça Furtado, somada à trajetória administrativa, coloca o pesquisador diante de uma historiografia complexa, em que, como foi mencionado no percurso aqui descrito, teve a questão da comunicação como impedimento de resoluções práticas na dinâmica de governo. Por meio desse embasamento sumário do período e da região que o presente trabalho aborda, é possível mensurar a importância da circulação das cartas como meio de comunicação interna e externa que se via acuada pela dificuldade geográfica de locomoção. Entretanto, esse era um dos meios, se não o mais comum e praticado meio de comunicação existente.

Das trinta e cinco cartas que serão editadas posteriormente e que foram encaminhadas a Francisco Xavier de Mendonça Furtado, dezoito foram enviadas por Gonçalo Pereira Lobato e Sousa, no período de 1756 1757. Gonçalo Pereira Lobato e Sousa governou a capitania do Maranhão no período de 1753 - 1761. Neste artigo, como já mencionado, será apresentada a edição semidiplomática da última carta da restrita seleção das trinta e cinco cartas destinadas a Francisco Xavier de Mendonça Furtado, datada de 10 de novembro de 1757 por Gonçalo Pereira Lobato e Sousa.

A relação entre o brigadeiro Gonçalo Pereira Lobato e Sousa e Francisco Xavier de Mendonça Furtado era próxima, como ressalta Santos (2008): “ A nomeação indica também a confiança no brigadeiro e no seu pertencimento a um círculo íntimo de colaboradores de Mendonça Furtado e de Sebastião de Carvalho e Melo" (SANTOS, 2008, p. 166). Ainda que sem experiência governativa, mas com vasta experiência militar, Gonçalo recebeu a tarefa de recuperar o Estado do Maranhão. Contudo, é possível identificar a constante intervenção de Francisco Xavier de Mendonça Furtado por meio da troca de correspondências entre os dois. As indicações mais destacadas dizem respeito ao período de governo de Gonçalo Pereira Lobato e Sousa no segundo e terceiro triênios de administração (1757-1761). 
O segundo e o terceiro triênios de Gonçalo Pereira (1757-1761)

foram voltados para a aplicação das leis de liberdade dos índios; a fundação de vilas a partir dos aldeamentos indígenas e a expulsão dos jesuítas[...] não é demais salientar as correspondências enviadas por Mendonça Furtado a Gonçalo Pereira, relativas à liberdade dos índios e ao trato com os missionários, em especial os jesuítas. Em suma, os passos do brigadeiro seguiram as indicações de Mendonça Furtado, fundadas no espírito do Diretório (SANTOS, 2008, p. 174-175).

"Sem cuja approvaçaõ me naõ atrevo a obrar nada"

91

Um análise filológica de determinado manuscrito mobiliza, inicialmente, o que seria sua essência documental, íntima, sua natureza (o que lhe confere, de alguma maneira, autonomia em seu domínio científico/original) e dimensões que extrapolam esse contexto primário, as quais são capazes de revelar uma outra realidade (relações contextuais, situacionais, políticas, sociais, linguísticas, históricas, que criam diálogos com diferentes áreas do conhecimento). Há um caminho a ser percorrido, caracterizado por uma transposição do texto como tal, de sua função e sentido primários, a seu caráter como fonte documental, filológica, linguística, literária, histórica, etc.

Nesse sentido, ao eleger o estudo de cartas da administração colonial, ou seja, de documentos em circulação pública no Brasil e em Portugal, não se está estudando somente uma prática epistolar com características próprias de sua espécie documental, estuda-se também como essas características dialogam com outros aspectos, históricos, políticos, culturais, etc. Dessa maneira, o olhar sobre os textos, sob um viés filológico, por exemplo, além de ser capaz de identificar particularidades da escrita do secretariado em questão, cuja história de alfabetização restringe-se, inicialmente, ao responsável material pela carta, revela também como essa escrita poderia constituir uma tradição gráfica setecentista, num contexto administrativo da região norte, com sua relação com o português europeu ou em constituição do que se configuraria como português do Brasil ainda não conhecida.

Se aspectos gráficos que dizem respeito ao uso do português em manuscritos do século XVIII continuam proporcionando importantes debates acadêmicos de acordo com os avanços referentes à história da 
língua portuguesa, por vias documentais, principalmente em relação à periodização do português ${ }^{4}$, ainda falta uma sistematização detalhada da escrita em diversos contextos e espécies documentais, para que possa servir como parâmetro de análise e de descrição do português ao longo

Phablo de sua história. Nesse sentido, continuam necessários e extremamente Roberto Marchis importantes a edição e o estudo de manuscritos de diferentes épocas.

Num contexto de escassos estudos de documentos da região norte Fachin setecentista, assume uma relevância muito significativa o contato com as fontes e a aproximação com todas as suas implicações históricas e linguísSilva ticas, munindo o pesquisador de ferramentas fundamentais para o entendimento do alcance científico desse tipo de estudo, principalmente no que se refere às complexidades em se estudar estágios pretéritos de língua por meio de fontes documentais, textos não-literários. Trata-se, na realidade, como afirmam Banza e Gonçalves (2018, p. 13), de um "exercício de reconhecimento das características e relações particulares entre oral e escrito que se estabelecem em cada texto, bem como das limitações e consequentes cautelas a ter na interpretação dos dados por eles fornecidos".

Composto por um total de quatro fólios, o documento ${ }^{5}$ eleito para o estudo possui dois fólios escritos em disposição vertical, um em branco e outro com disposição horizontal indicando um campo para "resposta". A disposição do fólio horizontal remete ao formato de um tipo de envelope. Por meio do suporte, é possível visualizar a escrita do verso da folha. Na parte superior esquerda observa-se a falta de um pedaço mais ou menos quadrado que é disfarçado por outro suporte abaixo possivelmente colocado para auxiliar no processo da digitalização. Na parte superior direita, observa-se uma inscrição tardia com uma numeração que identifica o manuscrito dentro do banco de dados da biblioteca. As margens do documento são regulares no decorrer do texto, assim como a paragrafação. Há um espaço menor anterior à saudação na margem superior, um maior na margem esquerda. Na margem direita, um espaçamento menor que o da margem esquerda. A mancha do texto ocupa todo o espaço do fólio de forma regular com os espaçamentos entre linhas regulares. $O$ outro lado, verso do primeiro, apresenta maior irregularidade nas margens, espaçamento entre linhas e alinhamento.

4 Proposta de periodização do português conforme Lucchesi (2017).

5 A descrição leva em conta uma certa limitação da análise, principalmente pelo fato de termos acesso ao manuscrito somente pelo meio digital. Entretanto, é possível realizar breves descrições sobre o material estudado. 
As saudações finais estão centralizadas com assinatura no canto inferior direito. O fólio horizontal é composto por três linhas horizontalmente dispostas do lado superior direito, com algumas marcas de inscrição posterior centralizado abaixo. $\mathrm{O}$ manuscrito possui trinta $\mathrm{e}$ nove linhas, incluindo as três do fólio horizontal.

Direcionada a Francisco Xavier de Mendonça Furtado, a carta serve de instrumento para a utilização de uma estratégia discursiva própria do período, por meio da qual se estabelece primeiro a proximidade entre os interlocutores, com o uso recorrente a formas de primeira pessoa, acompanhadas de elementos substanciais no processo de nomeação\caracterização do seu interlocutor, embora com o estatuto de formalidade exigido entre os agentes envolvidos. Assim, a parte inicial do manuscrito se caracteriza por "Meu General, e meu Senhor", seguidos por expressões

"Sem cuja approvaçaõ me naõ atrevo a obrar nada" de apreço, estima e subserviência, "determino pagar", "dizerme Sepoderey pedir", "sem cuja approvaçaõ me naõ atrevo abordar nada".

A contextualização pessoal tem grande importância na matéria a ser apresentada na carta, uma vez que era também de cunho pessoal\ particular o que seria descrito, situação problematizada pelas esferas envolvidas, a política e a religiosa. Tratava-se de um pedido de perdão, de um arrependimento de uma espécie de calúnia sofrida pelo autor intelectual do documento, mas sem resposta, a qual deveria vir primeiramente do seu destinatário, uma vez que o próprio não se demonstrava confortável em fazê-lo sem antes consultar Mendonça Furtado. É o que se observa ao ler a parte textual da carta, logo após a tentativa de captação de benevolência. A construção é válida tanto do ponto de vista do remetente ao destinatário quanto do religioso arrependido ao remetente. $O$ detalhe descritivo e conteudista apresentado compõe toda a dinâmica que constitui o documento e a sua complexa relação.

\footnotetext{
detarde meveyo aqui pedir dejoelhos. Frei | Iozê Iansen/persuadidoper Carta do Excelentissimo Senhor̃ Bispo dess aCidade[s] | que lheperdoasse, confessando asSuaz falsidadez do que escreveracontramim | e provando queofizera pior Diogo Manec, que [ ] o insultara á | of[end]ello] assim, que conhecia asSuas maldadez, aSuamâ Lingua e | coracaõ aque não attendesse, eSó perdoasse pella morte, epaixaõ de | Christo/ como hâ muitos lhe tenho perdoad o nomeu particullar, econfiço- | éz/eulherespondi duvidozo, ed aquifoy dizer omesmo ao Dezem | bar-
} 
Phablo

Roberto

Marchis

Fachin

Marina Pessoa

Silva

gadorProvedor, quemmedisse lhe deraChâ Sem assucar, pro- | guntandolhe comq́ue temord e Deoz ofizera, incluind ome, eaelle [pela] | Sua maldade edoutros emhuâ Suciedade na Fabrica d oCo queiro, | eque ofizesse delle, máo hera, máz daminhapureza pior, pelloque | Sefazia digno d omayor inso valho, Senaõ trouxesse aquelle habito (trecho da carta analisada).

Na sequência, o protocolo final traz o encerramento do texto por meio da certeza de serviço absoluto ao governador e capitão general, "Eeufico certo paraServir aVossa Excelencia noque memandar a fazer Deus guarde muitos annos".

Diante da proximidade estabelecida entre os interlocutores, de serviço, admiração e respeito por parte principalmente do autor intelectual da carta, Lobato e Sousa, como "Criado muito Ubrigado etodo | De Vossa Excelencia", revela uma escolha vocabular e sintática necessária, no processo discursivo, para alcançar o efeito desejado e para a prática de escrita em questão. Trata-se de relação de poder, estabelecida historicamente, norteada por um processo comunicativo próprio para reverberações políticas, reforçadas por escolhas gráficas que não são exclusivas da esfera administrativa colonial, que perpassam, provavelmente, por outros contextos expressivos de diversas instâncias de poder.

Diante desse cenário, cabe ao pesquisador identificar qual o caminho adequado a seguir em busca de verificar como o papel da escrita se caracterizava nesse contexto, a quais camadas linguísticas e sociais o estado de língua testemunhado pelo documento se refere: primeiramente a refletida pelo conhecimento linguístico do escriba e sua habilidade em manusear e aplicar instrumentos de escrita, ou seja, a sua familiaridade com a técnica e a prática da escritura, depois com a própria tradição documental, suas fórmulas e termos cristalizados ao uso de determinado contexto de escrita, tendo em vista as relações sociais e de poder presentes.

Quanto à escrita do documento, observa-se uma homogeneidade em relação ao módulo (altura dos caracteres gráficos) dos grafemas ${ }^{6}$, às formas dos traços dos alógrafos utilizadas e ao respeito às pautas e

\footnotetext{
6 "alógrafos estão para o grafema assim como os alofones para o fonema. Enquanto realidade fônica perceptível pela audição, o fonema é o referencial necessário para o alofone. Assim, pois, como o fonema, menor segmento fônico desprovido de sentido, tem por variante o alofone, o morfema, signo mínimo com significação, tem o alomorfe, e o grafema, a unidade de um sistema de escrita, o alógrafo" (MEGALE et al, 2007, p. 130).
} 
às linhas, ainda que não visíveis. Com aspecto cursivo, inclinado para direita, apresenta alguns ornamentos, principalmente nos alógrafos do grafema $<\mathrm{d}>$ e nas iniciais de cada parágrafo. Há junção de algumas palavras na escrita quase que como uma não retirada da mão ao escrever ${ }^{7}$, que pode indicar uma certa agilidade por parte de quem escreveu a carta, ou ainda uma limitação espacial, decorrentes dos hábitos gráficos do seu autor material ${ }^{8}$. Outro processo interessante e recorrente na escrita setecentista em questão é o uso de abreviaturas. Na carta, esse recurso aparece de forma semelhante à caracterizada por Spina (1977, p. 45): “a) abreviaturas por sigla, b) abrev. por apócope, c) abrev. por síncope, d) abrev. por letras sobrepostas, e) abrev. por signos especiais de abreviação, e f) letras numerais."

\section{"Sem cuja approvaçaõ me naõ atrevo a obrar nada"}

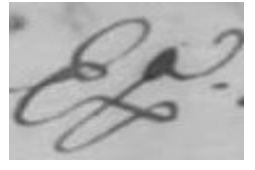

Excelencia

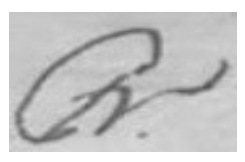

Frei

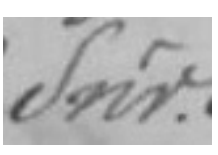

Senhor

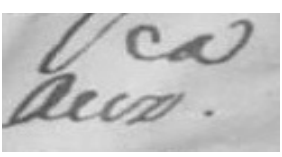

auzencia

$\mathrm{Na}$ composição linguística do documento analisado, há certa regularidade, ou seja, a escolha do escriba apresenta pouquíssimas oscilações dentro do próprio manuscrito, podendo indicar um uso da língua que pode compor uma tradição gráfica em construção9. Das 284 palavras que a carta exibe, 104 são grafadas com sibilantes. Dentre essas representações, aparecem os grafemas $\langle$ s $>,\langle$ ss $>,\langle$ c $>,\langle c ̧>$, e $\langle\mathrm{Z}>$. Para representar as consoantes surdas, por exemplo, utiliza-se $o<s>$ inicial na maioria das palavras. Alguns exemplos são: Senhor, SeSirva, Sem, asSuaz, asSuas, Suciedade, Senão. É possível identificar outras ocorrências que seguem essa dinâmica. Em contexto inicial identificaram-se apenas duas ocorrências que não são representadas pelo grafema $<$ s $>$ e sim por $<$ c>. São elas: Cidade e certo. Em posição medial, o grafema <s> destaca-se na palavra persuadido, falsidadez e insitara. A representação gráfica $<\mathrm{x}>$ aparece uma vez na palavra exacto. Em posição final, $<\mathrm{s}>\mathrm{e}<\mathrm{Z}>$. A análise

7 Na edição, optou-se por respeitar as fronteiras entre as palavras, conforme aparece no documento.

8 O detalhamento desses processos serão analisados juntamente com as demais cartas. Por enquanto, para a proposta deste artigo, alguns aprofundamentos serão limitados, ficando apenas no campo do comentário e da descrição.

9 Pretende-se, com a análise das demais cartas, identificar aspectos que possam caracterizar uma possível tradição gráfica. 
desses usos mostra certa regularidade na escrita do escriba, isto é, no decorrer da carta não aparecem muitas variações de grafemas e alógrafos para uma mesma palavra.

É interessante observar, contudo, como um único documento,

Phablo embora com esse caráter regular de escrita, também pode ser tão reveRoberto lador histórica e linguisticamente, com um alcance histórico muito sigMarchis nificativo tendo em vista as mudanças ocorridas no português ao longo Fachin dos séculos XV, XVI e XVII, muitas delas consolidadas ou próximas disso já no século XVIII. As ocorrências a seguir exemplificam tal constatação:

Marina Pessoa

Silva dezaSeis; poderey, veyo, mayor, foy, estimarey, perejra; approvaçaõ, attendesse, pella, particullar, elle, delle, aquelle, effeito, permittir, officiaes; Iozê, Iansen, Jansen; suaz, maldadez, confissoez, duvidozo, todoz, ambaz; assucar, dice; Suciedade, involveo, menhã; huã, hum, Hé; nam, Maranham. Trata-se de elementos relacionados a diversos fenômenos. Alguns deles dependentes do próprio processo de escrita, de manuseio da pena sobre o papel, portanto meramente gráficos, outros com uma abrangência mais complexa, considerando o usuário da língua, sua história, local de produção, etc. Esses resultados revelam a importância da edição de textos em língua portuguesa e o seu estudo sob o ponto de vista filológico e da história da língua, incorporados em estudos diacrônicos, de descrição e análise linguística.

Um olhar mais amplo sobre aspectos do estado de língua presente na carta, tendo em vista as transformações pelas quais o português passou, revela importantes particularidades. No contexto vocálico, em casos como os encontrados em dezaseis, suciedade, involveo, menhâ e proguntam. No consonântico, em palavras com consoantes geminadas, oscilação entre grafemas $<\mathrm{i}>\mathrm{e}<\mathrm{j}>$ e no uso de sibilantes. Identificar e compreender como essas particularidades se caracterizam e o quanto podem contribuir para o conhecimento a respeito da história da língua portuguesa são, como afirma Maia (1986, p. 950), uma forma de "compreender a verdadeira natureza da língua escrita dos documentos".

A relação de proximidade constituída pela produção da carta e a permeação de instâncias de poder presentes, a escrita do documento, sua composição vocabular e sintática, causam um efeito que transcende a natureza primeira do documento, como mero instrumento de comunicação entre agentes da administração colonial. Uma natureza que se revela complementarmente por meio de seus elementos materiais, grafemas, alógrafos, espécie documental, e aspectos linguísticos, 
o próprio sistema de escrita, cujas implicações abrangem também fatores sociolinguísticos, os quais contribuem para o conhecimento da língua utilizada e da própria dinâmica de correspondências no contexto em questão.

Esse conjunto de elementos, particularizados na carta selecionada para este artigo, constitui pistas para o alcance de um quadro linguístico e histórico mais amplo, capaz de revelar características da escrita setecentista na região norte em contexto administrativo e ampliar o conhecimento sobre a história da língua portuguesa, sua periodização e sociedade. Trata-se do caminho a ser percorrido com base em manuscritos produzidos no século XVIII na região conhecida como Grão-Pará e Maranhão.

"Sem cuja approvaçaõ me naõ atrevo a obrar nada"

\section{Conclusão}

Este trabalho teve como principal objetivo trazer à tona uma proposta de análise de correspondências enviadas a Francisco Xavier de Mendonça Furtado, governador e capitão general no Estado do Grão-Pará e Maranhão, por meio do estudo e da edição semidiplomática de carta enviada por Gonçalo Pereira Lobato e Sousa, datada de 10 de novembro de 1757, a fim de iniciar as discussões que permeiam a administração colonial do século XVIII na região em questão, considerando os usos da língua no processo de formação e consolidação da língua portuguesa.

A edição das trinta e cinco cartas se faz necessária para se compor uma trajetória e análise linguística que consiga identificar e estudar as práticas de escrita presentes na documentação editada, pois assim será possível verificar os hábitos de escrita setecentista entre os administradores e entre as pessoas comuns que compunham aquele espaço, para comparar com o que já é conhecido sobre o século XVIII em torno da história do português com o intuito de somar para o avanço das pesquisas em torno da língua portuguesa.

Para além disso, a busca, a observação e a análise da história da circulação dessas cartas revelam o processo de comunicação estabelecido por esses administradores coloniais, uma vez que, o próprio Francisco Xavier de Mendonça Furtado reitera a dificuldade interna de comunicação no Brasil, isto é, de acordo com a história geográfica da região e seus avanços, os desdobramentos históricos do cotidiano, as influências internas e externas. Com isso, os resultados alcançados para o estudo da língua contribuem para diversos trabalhos que visem ao período colo- 
nial e às suas particularidades pelo viés do trabalho filológico, da edição e estudo de documentos manuscritos, fundamentais para a constituição genuína da história social e linguística da comunidade lusófona.

Por meio da análise de apenas uma das trinta e cinco cartas, foi

Phablo possível considerar aspectos estruturais da Língua Portuguesa influenRoberto ciados pelo meio em que estão inseridos, assim como por suas impliMarchis cações sociolinguísticas, históricas e com os agentes participantes desFachin sas interações. A disposição estrutural observada na carta enviada por Gonçalo Pereira Lobato e Sousa configura-se dentro de uma ideia já co-

Marina Pessoa

Silva nhecida em torno do tipo de padronização documental, contudo ainda sendo possível confrontá-la com as demais cartas analisadas, tal qual com as de outros agentes participativos diretos ou não da administração colonial e seus desdobramentos.

A breve disposição em torno de aspectos linguísticos e textuais nos revela questões que nos cercam até os dias de hoje, em que a confusão gráfica apresenta-se em diversas situações e contextos, podendo ser reveladoras de importantes mudanças linguísticas. Daí a importância de sua análise de forma contextualizada, com base em edições fidedignas, e um processo de análise mais detalhado, com mais documentos, por meio de elementos que possam auxiliar no percurso do quadro linguístico apresentado e de outros ainda a serem levantados. Assim, observa-se que o século XVIII representa, em diversas dimensões, um importante contexto de pesquisas, e vasta fonte de conhecimento.

\section{REFERÊNCIAS}

ACIOLI, Vera Lúcia Costa. A escrita no Brasil Colônia: um guia para leitura de documentos manuscritos. Recife: UFBA, Fundação Joaquim Nabuco, Massangana, 1994.

BELLOTTO, Heloísa Liberalli. Como fazer análise diplomática e análise tipológica de documentos de arquivo. São Paulo: Arquivo do Estado e Imprensa Oficial do Estado, 2002.

CAMBRAIA, César Nardelli; CUNHA, Antônio Gerado da; MEGALE, Heitor. A Carta de Pero Vaz de Caminha. São Paulo: Série Diachronica, 1, Humanitas, 1999. 
CASTRO, Ivo. Introdução à História do Português. Lisboa: Edições Colibri, 2006.

FACHIN, Phablo Roberto Marchis. Implicações gráficas e autorais no processo de produção e circulação de manuscritos no Brasil colonial. Rio de Janeiro: Labor Histórico, 2016.

FONTANElle, Francisca Nescylene. Grão-Pará Pombalina: "Sem cuja trabalho, desigualdade e Relações de Poder. Dissertação approvaçaõ me (Mestrado em História) - Universidade Católica de São Paulo. naõ atrevo a São Paulo, 2008.

MAIA, Clarinda de Azevedo. História do Galego-Português. Estado 99 linguístico da Galiza e do Noroeste de Portugal desde o século XIII ao século XVI (Com referência à situação do galego moderno). Coimbra: Instituto Nacional de Investigação Científica. 1986.

MONTE, Vanessa Martins do. Documentos setecentistas: edição semidiplomática e tratamento das sibilantes. 2007. Dissertação (Mestrado em Filologia e Língua Portuguesa) - Faculdade de Filosofia, Letras e Ciências Humanas, Universidade de São Paulo. 2007.

LUCCHESI, Dante. A periodização da história sociolinguística do Brasil. DELTA [online]. 2017, vol.33, n.2, pp.347-382.

SANTIAGO-ALMEIDA, M. M. Aspectos fonológicos do português falado na baixada cuiabana: traços de língua antiga preservados no Brasil (Manuscritos da época das Bandeiras, século XVIII). São Paulo. Tese (Doutorado). "Faculdade de Filosofia, Letras e Ciências Humanas, Universidade de São Paulo." 2000.

SANTOS, Bruna Trindade Lima. Edição do Plano Sobre a Civilização dos Índios do Brasil: contribuições para aspectos sócio-históricos do português no Brasil do século XVIII. Dissertação (mestrado em Ciências da Linguagem). Faculdade de Ciências Sociais e Humanas - Universidade Nova de Lisboa, 2016. 
SANTOS, Fabiano Vilaça dos. 0 governo das conquistas do norte: trajetórias administrativas no Estado do Grão-Pará e Maranhão (1751-1780). Tese (Doutorado em História Social) - Faculdade de Filosofia, Letras e Ciências Humanas. Universidade de São Paulo.

Phablo São Paulo, 2008.

Roberto

Marchis SPINA, Segismundo. Introdução à Ecdótica: crítica textual. São

Fachin Paulo, Cultrix. Ed. da Universidade de São Paulo, 1977.

Marina Pessoa

Silva

100 